\title{
IMPORTANCE OF NATURAL TEST CONDITIONS IN ASSESSING THE SENSORY STATE OF THE SQUINTING SUBJECT* WITH SOME CLINICAL CONSIDERATIONS ON ANOMALOUS RETINAL CORRESPONDENCE
}

\author{
BY \\ LUIGI PASINO AND GIOVANNI MARAINI \\ From the University Eye Clinic (Director: Prof. P. Matteucci), Parma, Italy
}

THESE observations made while examining squinting subjects in normal surroundings are based on our daily practice in the Orthoptic Department of the University Eye Clinic in Parma, confirmed by a more detailed study of 112 patients followed-up for an average period of 2 years. Two problems received particular attention:

(1) The clinical importance of non-dissociating test conditions in the exact assessment of retinal correspondence in normal surroundings.

(2) The relationship between the sensory state assessed in normal surroundings and the nature and extent of the ocular deviation.

The present paper is concerned with a well-defined type of strabismus which represents, in our experience, an unsolved problem in this field, i.e. constant manifest strabismus of early onset (before the 3rd birthday).

In all the patients examined (aged from 6 to 18 years) the visual acuity was good in both eyes (not less than 5/10 with the Monnoyer test chart) because the strabismus was alternating or because the amblyopia had been at least partly cured.

The clinical examination was carried out in normal surroundings using Bagolini's striated glasses with the aid of a bar of red filters in the presence of deep suppression (Bagolini 1957, 1958). These glasses are transparent lenses superficially streaked on one surface so that a thin luminous line appears against a light source while the perception of the surroundings is unchanged (Fig. 1).

FIG. 1.-Appearance of streaks seen with Bagolini's striated glasses.

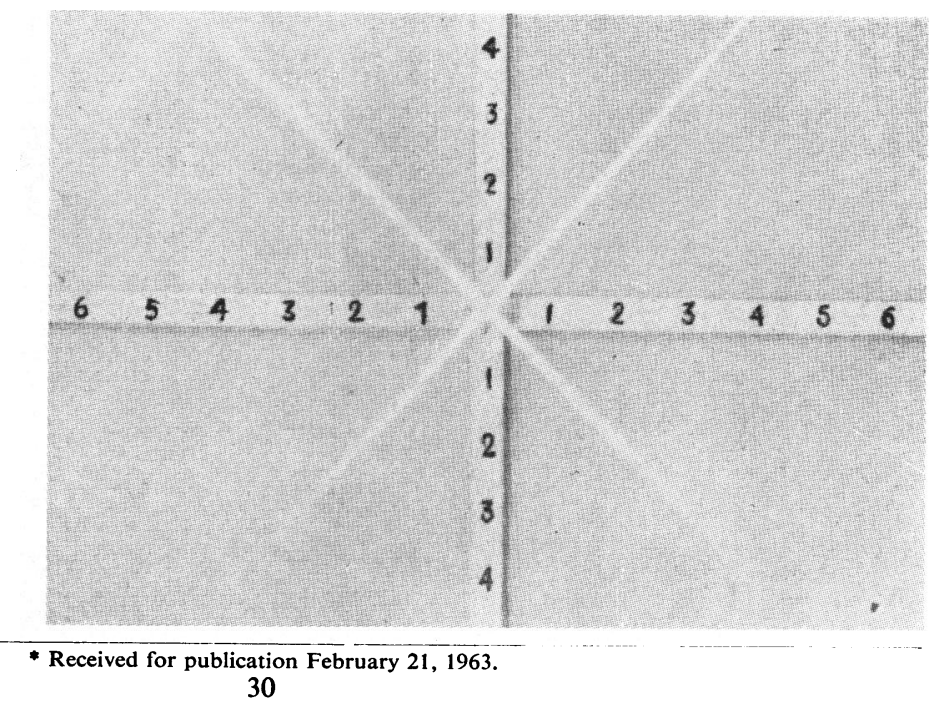


The results obtained in 106 patients with the striated glasses, the synoptophore, and the Bielschowsky after-image test are summarized in Table I, which shows that many patients with normal or unharmonious anomalous retinal correspondence according to the synoptophore or after-image test are found to have harmonious anomalous retinal correspondence when examined with Bagolini's glasses. This is the most frequent sensory anomaly provided that deep suppression is not present.

TABLE I

RESULTS OF TESTS IN 106 PATIENTS (PER CENT.)

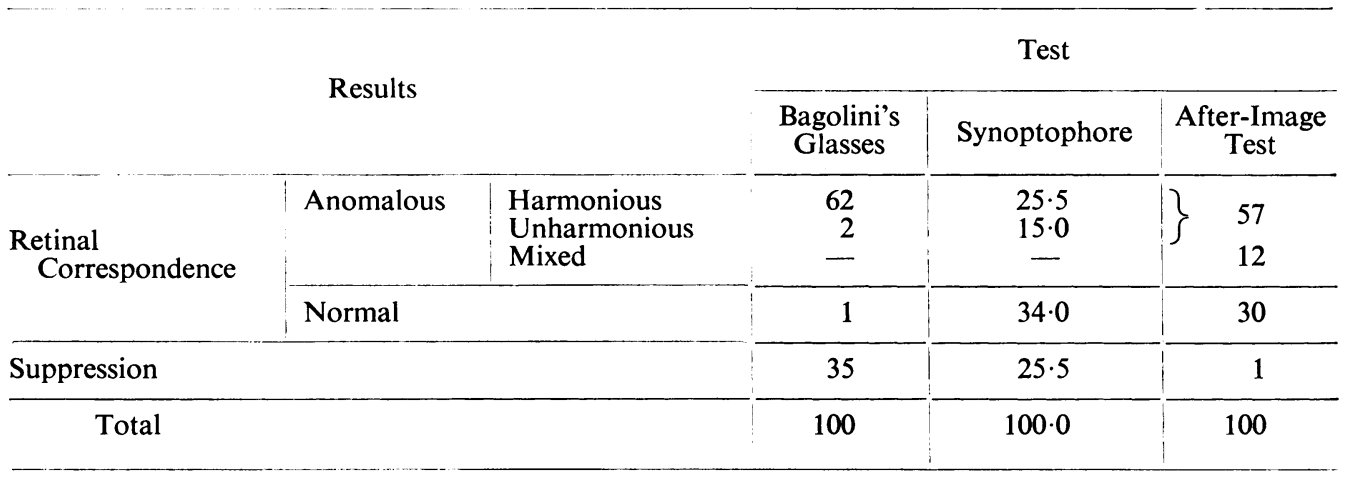

Fig. 2 summarizes the relationship between the sensory state as determined with the striated glasses and the type and degree of the angle of deviation (measured in prism dioptres at a distance of $5 \mathrm{~m}$.); nearly all the subjects were tested more than once as the angle of squint was reduced with treatment. The percentage of cases

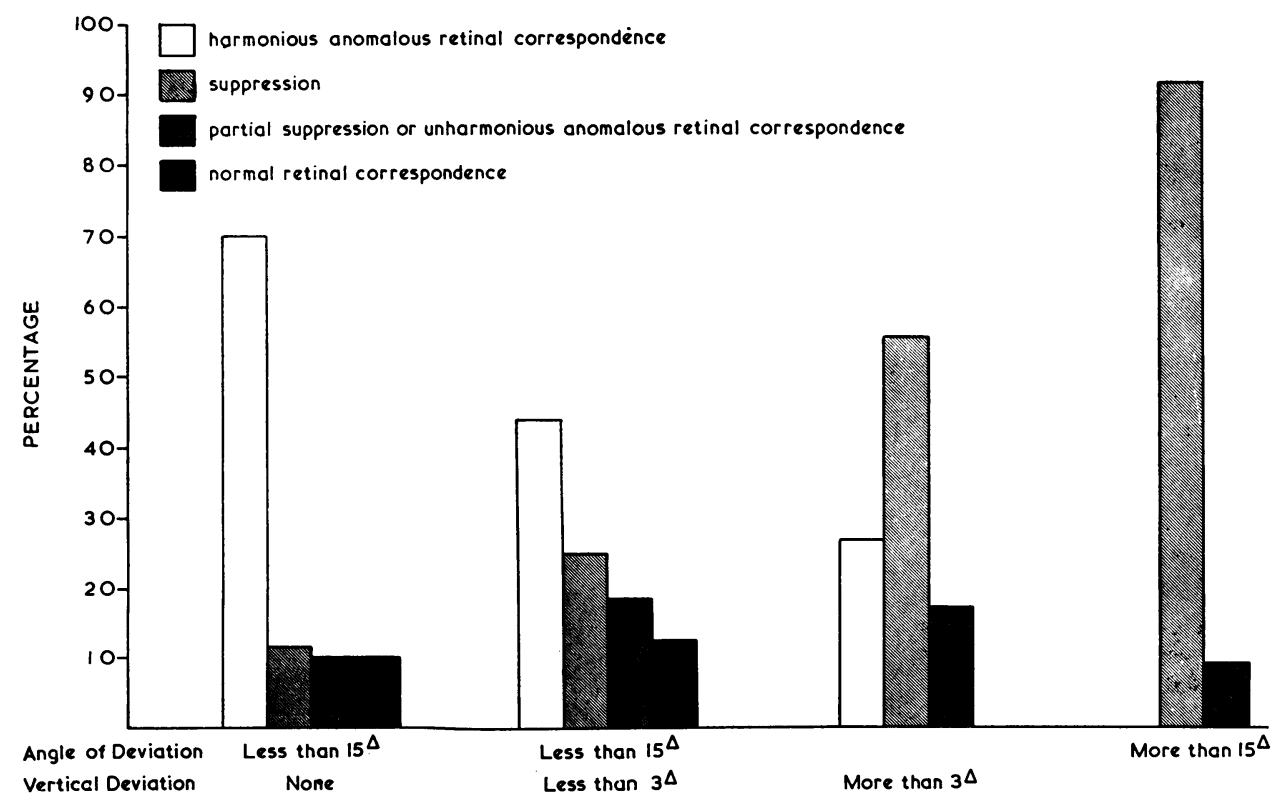

Fig. 2.-Sensory state related to angle of deviation and presence of vertical deviation. 
with harmonious anomalous retinal correspondence increases progressively with the decrease of the angle of deviation particularly in the absence of vertical deviation. Suppression is the most common sensory alteration when the angle of deviation is large. Unharmonious anomalous retinal correspondence is most frequently observed with medium angles of deviation, especially in association with vertical deviation.

A more detailed analysis has been made of 42 patients with small angles of deviation and harmonious anomalous retinal correspondence; the disparity of the stimulated retinal points was increased by introducing base-in prisms not exceeding 9 prism diopters.

By means of the striated glasses we observed that in 34 of the 42 cases when the ocular deviation was altered there was an identical change in the angle of anomaly leading to the establishment of a new harmonious anomalous retinal correspondence; in only eight cases did unharmonious anomalous retinal correspondence, suppression, or even diplopia appear.

The data referring to eighteen of these patients are set out in Table II; the difference existing between the change in the deviation could be interpreted as evidence of an incomplete fusional movement followed by the modification of the angle of anomaly, but this interpretation is not tenable in cases not showing anomalous fusion.

TABLE II

EFFECT OF PRISM IN EIGHTEEN SELECTED CASES OF HARMONIOUS ANOMALOUS RETINAL CORRESPONDENCE

\begin{tabular}{c|c|c|c|c|c}
\hline $\begin{array}{c}\text { Case } \\
\text { No. }\end{array}$ & $\begin{array}{c}\text { Objective } \\
\text { Angle of } \\
\text { Deviation } \\
\text { (D) }\end{array}$ & $\begin{array}{c}\text { Prism } \\
\text { Base-in } \\
\text { (D) }\end{array}$ & $\begin{array}{c}\text { Objective } \\
\text { Angle of } \\
\text { Deviation with } \\
\text { Prism (D) }\end{array}$ & $\begin{array}{c}\text { Sensory } \\
\text { Anomaly }\end{array}$ & $\begin{array}{c}\text { Difference between } \\
\text { Observed and } \\
\text { Expected Angle } \\
\text { of Deviation }\end{array}$ \\
\hline 1 & +4 & 6 & +8 & h.a.r.c. & -2 \\
6 & +2 & 7 & +8 & h.a.r.c. & -1 \\
7 & +1 & 7 & +4 & h.a.r.c. & -4 \\
8 & +3 & 4 & +6 & u.a.r.c. & -1 \\
9 & +1 & 7 & +5 & u.a.r.c. & -3 \\
10 & +2 & 6 & +4 & suppression & -4 \\
12 & +8 & 9 & +12 & diplopia & -5 \\
13 & +3 & 9 & +6 & h.a.r.c. & -6 \\
14 & +12 & 7 & +17 & suppression & -2 \\
16 & +1 & 9 & +2 & u.a.r.c. & -8 \\
18 & $\mathbf{L} 1$ & 8 & +7 L/R $1 \Delta$ & h.a.r.c. & -1 \\
20 & +2 & 8 & +8 & h.a.r.c. & -2 \\
21 & +15 & 8 & +23 & h.a.r.c. & -6 \\
23 & +3 & 7 & +4 & h.a.r.c. & h.a.r.c. \\
26 & +2 & 4 & +6 & h.a.r.c. & -5 \\
30 & $\mathbf{+ 3}$ & 9 & +7 & h.a.r.c. & -3 \\
33 & +6 & 6 & +3 R/L $1 \Delta$ & h.a.r.c. & -2 \\
\hline
\end{tabular}

\section{Discussion}

(1) That a patient's behaviour differs when he is subjected to different test conditions has already been observed by Hugonnier and Hugonnier-Clayette (1962) and Lyle (1962); the more the conditions of everyday life are approached by excluding the dissociation methods of examination, the more frequently is harmonious ano- 
malous retinal correspondence recorded. This harmonious anomalous retinal correspondence is often detected in patients who show unharmonious anomalous retinal correspondence or normal retinal correspondence when tested under other conditions. Bagolini and Tittarelli (1960) found a higher frequency of harmonious anomalous retinal correspondence $(83.4$ per cent.) with striated glasses than with the Worth test (33.9 per cent.) or with the synoptophore (12.6 per cent.).

(2) The sensory state of the patient is influenced, in free space, by the type and degree of the ocular deviation. Large-angle strabismus is normally associated with suppression, and vertical deviations of more than 4 prism dioptres usually cause suppression or unharmonious anomalous retinal correspondence; the smaller the angle of deviation, particularly if there is no vertical element, the higher the percentage of harmonious anomalous retinal correspondence.

In considering the relationship between retinal correspondence and the angle of deviation, various authors have reached different conclusions. Adler and Jackson (1947), Flom (1958), Pugh (1954), and Kretzschmar (1955) stated that anomalous retinal correspondence was rare in cases of small-angle strabismus, but Strazzi (1950) and Stephenson (1950) found no relationship between the type of retinal correspondence and the angle of deviation. Jampolsky (1951), on the other hand, claimed that 90 per cent. of patients with a deviation of less than 15 prism dioptres had anomalous retinal correspondence.

These discrepancies may be explained by the fact that dissociating tests were used which do not permit an accurate diagnosis of the sensory state when the deviation is small. Moreover, as Kretzschmar (1955) and Burian (1958) have shown, many of these patients have an intermittent or accommodative strabismus which is completely different from the type of squint dealt with in this paper.

Bagolini and Tittarelli (1960), using Bagolini's striated glasses, investigated a group of 100 patients and their results were the same as ours. Furthermore, we have found that the presence of a vertical deviation with a small horizontal deviation is an important obstacle to harmonious anomalous retinal correspondence, and leads to unharmonious anomalous retinal correspondence or to suppression.

(3) We have found that, contrary to traditional orthoptic opinion, harmonious anomalous retinal correspondence is not an irreversible or hardly modifiable sensory condition; it would seem on the contrary to be rather a plastic phenomenon closely linked to the size of the angle of deviation and may change as the angle changes.

The possibility that the angle of anomaly may vary has already been admitted by some authors (Burian, 1958; Hallden, 1952; Kretzschmar, 1955). Swan (1948) asserted that the angle of anomaly could be adapted to the angle of deviation and we have found this to be the rule rather than the exception.

Opinion differs on the practical importance of this rudimentary form of binocular vision; Burian (1941), Hallden (1952), and Lyle (1962) have claimed that fusional movements can be elicited in such patients, but Kretzschmar (1955) held the opposite view. Our data obviously do not permit conclusions to be drawn, but we regard this problem as a very important one which needs to be extensively studied under natural test conditions. 


\section{Summary}

(1) The clinical examination of the binocular vision of a squinting subject must be carried out in the most natural test conditions since the dissociation tests in current use do not suffice to define exactly the characteristics of the sensory anomaly.

(2) Muscular imbalance is a most important factor in determining the patients' sensory state.

(3) A very small vertical deviation may favour the onset of unharmonious anomalous retinal correspondence and enhance the tendency to suppression.

(4) Harmonious anomalous retinal correspondence may adapt itself to small variations in the angle of deviation.

\section{REFERENCES}

Adler, F. H., and JACKSON, F. E. (1947). Arch. Ophthal. (Chicago), 38, 289.

BAGOLINI, B. (1957). Boll. Oculist., 36, 638. (1958). Ibid., 37, 158.

and Tittarelli, R. (1960). Ibid., 39, 211.

Burian, H. M. (1941). Arch. Ophthal. (Chicago), 26, 626.

(1958). In "Strabismus Ophthalmic Symposium II", ed. J. H. Allen, p. 184. Mosby, St. Louis.

Flom, M. C. (1958). Amer. J. Optom., 35, 69, 509. Cited by Burian, 1958.

Hallden, U. (1952). Acta ophthal. (Kbh.), Suppl. 37.

HugonNiER, R., and HugONNIER-ClAYETTE, S. (1962). In "Encyclopédie médico-chirurgicale", Ophtalmologie, vol. 3. 21550 A20. Paris.

Jampolsky, A. (1951). A.M.A. Arch. Ophthal., 45, 18.

KRETZSCHMAR, S. (1955). Docum. Ophthal., 9, 46.

LYLE, T. KeITH (1962). Personal communication.

Pugh, M. (1954). Brit. J. Ophthal., 38, 321.

StePHENSON, R. W. (1949). Trans. ophthal. Soc. U.K., 69, 549.

Strazzi, A. (1950). Boll. Ocul., 29, 517.

SWAN, K. C. (1948). Arch. Ophthal. (Chicago), 40, 371. 